\title{
Designing a Cross-Cultural Collaborative Online Learning Framework for Online Instructors
}

\author{
Alex Kumi-Yeboah \\ University at Albany-SUNY, New York
}

\begin{abstract}
Online education has now become an integral part of the educational landscape in the United States and around the world, where it serves as the primary source of enrollment growth in higher education. The rising student population in online learning mandates instructors and instructional designers to be aware of the importance of cultural factors that influence students' learning experiences and academic performance in online environments. This study explored instructors' perspectives on designing a cross-cultural collaborative online learning framework. Particularly, instructional strategies that promote designing a cross-cultural collaborative online learning framework. It also investigated challenges instructors face in designing a cross-cultural collaborative online learning framework. Drawing on collaborative online learning theory, this study analyzes qualitative interview data and online activities of 40 online instructors from two universities. Results show the following themes: (a) instructional strategies that facilitate crosscultural collaborative online learning, namely, group work, self-introductions and cultural awareness activity, computer-supported collaborative learning activity, the inclusion of global examples, and internationalized curriculum and (b) challenges of designing a cross-cultural collaborative online learning framework and teaching diverse learners. Findings suggest the need for online instructors to be trained in the best pedagogical practices to promote cross-cultural collaborative activities in online learning environments.
\end{abstract}

Keywords: Cross-cultural collaborative learning, culturally diverse learners, collaborative learning activities, instructional strategies, online instructors, collaboration in online learning

Kumi-Yeboah, A. (2018). Designing a cross-cultural collaborative online learning framework for online instructors. Online Learning, 22(4), 181-201. doi:10.24059/olj.v22i4.1520

\section{Designing a Cross-Cultural Collaborative Online Learning Framework for Online Instructors}

Online education has now become an integral part of the educational landscape in the United States and around the world, where it serves as the primary source of enrollment growth in higher education (Allen \& Seaman, 2017). The rising student population in online learning mandates instructors and instructional designers to be aware of the importance of cultural factors that influence students' learning experiences and academic performance in online environments (Allen \& Seaman, 2016). The increased growth rate of online learning is attributed to the growth 
and use of technology as a means of instructional delivery for the majority of higher education institutions, rising tuition costs, an evolving workforce seeking lifelong learning options, and academic leaders' strategic focus to develop online learning strategies (Allen \& Seaman, 2017).

Collaborative learning is a pedagogical approach which helps to promote learning performance and deeper learning, i.e., critical thinking to master core academic content and solve complex problems (Blasco-Arcas, Buil, Hernandez-Ortega, \& Javier Sese, 2013; McDonough \& Foote, 2015). Other studies (Hiltz \& Turoff, 2002; Turoff, Hiltz, Li, Wang, \& Cho, 2004) have found that collaborative learning makes online learning proactive, active, or even more effective than that in the traditional face-to-face class. Integrating online courses with online collaborative learning provides access and opportunity for students to work together in online learning environments (Macdonald, 2003).

Furthermore, Yamazaki and Kayes (2004) suggest that educators and researchers need to understand cross-cultural collaborative learning as: (a) building relationships - interacting with others regularly, particularly with members of the host culture, (b) valuing people of different cultures - expressing interest and respect for the host culture, including its history, customs, and beliefs; (c) listening and observing - spending time observing, reading about, and studying the host culture, particularly with members of the host culture; (d) coping with ambiguityunderstanding ambiguous situations and making sense of new experiences; and (e) translating complex information - translating personal thoughts into the language of the host culture. For example, the rapid growth of diverse students in online learning demands further investigation about what type of instructional strategies instructors should use to facilitate cross-cultural collaborative learning to offer opportunity for diverse learners to participate and contribute to knowledge building in online learning environments (Gu, Wang, \& Mason, 2017; Yang et al., 2010).

Cross-cultural collaborative learning promotes construction of knowledge through interaction, co-construction, engagement, and negotiation with peers and instructors in online classrooms (Baker, \& Taylor, 2010; Kearney, 2004; Powell \& Kalina, 2009; Schreiber \& Valle, 2013). It provides students an opportunity to critically explore their own views, respond to different and challenging views of peers, and mutual understanding (Schreiber \& Valle, 2013). Powell and Kalina (2009) argued that collaborative learning improves the internalization of knowledge with the opportunity to do critical reflection and examine personal views or thoughts, respond to the multiple and challenging views of colleagues, and negotiate shared understandings (Schreiber \& Valle, 2013).

Mittelmeier et al. (2017) contend that future research needs to be conducted on best practices (i.e., to create a supportive online course community; use of large and small groups to foster interaction and create discussion posts with responses, questions, and reflections) and an instructional framework in online teaching to support and build interpersonal and intercultural skills that are necessary to work successfully with diverse students in online collaborative learning environments (Slof, Nijdam, \& Janssen, 2016). However, few empirical studies have investigated the design and implementation of cross-cultural collaborative online learning frameworks for online instructors. Particularly lacking is research on how instructors design cross-cultural collaborative online activities to help meet the needs of diverse learners (Hannon \& D'Netto, 2007; Hew, 2018; Yang, Kinshuk, Yu, Chen, \& Huang, 2014). To address this gap, this study utilizes a qualitative research design with 40 online instructor participants from two universities in Northeastern United States to test instructors' perspectives on designing instructional strategies 
that facilitate cross-cultural collaborative online learning frameworks. In the following sections, this study will highlight significant research on cross-cultural collaborative online learning, and the prospects, challenges, and conceptual frameworks related to collaborative online learning.

\section{Review of Related Literature}

Watson, Ho, and Raman (1994) defined culture as "the beliefs, value systems, norms, mores, myths, and structural elements of a given organization, tribe, or society" (p. 46). Scholars (Gunawardena et al., 2001; (Parrish \& Linder-vanberschot, 2010) stated that cultural differences in online learning have an adverse effect on students' participation in online courses. Gunawardena and Jung (2014) stated "culture impacts every facet of online learning, from course and interface design, to communication in a sociocultural space, and to the negotiation of meaning and social construction of knowledge" (p. 1). According to Subramony (2004), little attention has been paid to the equitability of distance learning and the surrounding cultural issues of instructional design in online learning, resulting in the alienation of many students.

Hannon and D'Netto's study (2007) on cultural awareness in online learning explored how a culturally diverse cohort of students engages with the organizational, technological, and pedagogical aspects of online learning. The authors surveyed 241 students in online learning programs in a large university in South Australia. The findings showed that cultural differences had an impact on students' satisfaction with organizational and technological issues, with local respondents indicating significantly more positive perceptions than international respondents. Results also showed students' lack of peer engagement and intercultural communication. The authors suggest the need for online instructors to construct a culturally inclusive online learning environment to improve the quality of learning for all students.

Mittelmeier, Rienties, Tempelaar, Hillaire, and Whitelock (2018) conducted a quantitative study that used a randomized control trial method with 428 undergraduate students in an introductory statistics course that compared individual and group-level participation in an online collaborative task. The findings showed that internationalization of online content facilitated individual-level participation and decreased the disparity of participation within small groups when the content is situated in countries that are personally relevant to students' own backgrounds.

Conversely, other studies (Bliss \& Lawrence, 2009; Dawson, 2006) found that online collaboration tools have the potential to promote learners' sense of community, increase the knowledge flow between students and facilitate their participation in online environments (Hrastinski, 2006). Research has revealed that many students prefer to work with peers from their own cultural backgrounds (Moore \& Hampton, 2015; Rienties et al., 2013). This is due to cultural distances between group members that make collaboration challenging (Fozdar \& Volet, 2012) and promote uncertainty (Strauss \& Young, 2011). Other studies (Mittelmeier et al., 2017; Popov et al., 2012) stated that some students are frustrated in intercultural collaboration as a result of unequal participation in online classrooms.

Popov et al., (2012) conducted a study on students' contributions to group participation in online learning. The authors found that the lack of group participation in intercultural group work was the major complaint of participants. This results from sociocultural tensions students face while working with peers from different backgrounds. Relatedly, Yang, Huiju, Chen, and Huang (2014) conducted mixed methods research on strategies that facilitate smooth and effective cross- 
cultural online collaborative learning of students from Chinese and American universities. The findings revealed that students from both countries showed interest in each other's culture, their attitudes to cross-cultural online collaborative learning were positive, and culture had an influence on learning methods. Furthermore, social interactions, past knowledge of students' cultural backgrounds, and personal dialogues emerged as strategies that facilitate effective cross-cultural online collaborative learning.

Zhong's (2010) study investigated the cultural influence in Computer-Supported Collaborative Learning (CSCL) on the expression of cultural values as individual characteristics and the ways that these values could determine technology acceptance and use. She found that in CSCL the "cultural influence in CSCL is multi-faceted" (p. 168) and that the "cultural dimension is an important factor in affecting the collaborative process, directly or indirectly, and the learning outcomes in CSCL" (p. 178). More so, Gu, Wang, and Mason (2017) conducted a study that explored the relationship between cultural factors and emerging roles among collaborating students from two universities in different countries (China \& USA). Their findings showed a significant correlation between student thinking styles and adopted roles of students in CSCL. Results called on online instructors to understand the cultures of diverse learners with different cultural backgrounds to facilitate the efficiency of cross-cultural CSCL.

Pei-Hsuan (2010) examined online instructors' perceptions of teaching experiences occurring in their own countries (Australia, Canada, China, United Kingdom, United States, and Taiwan). Results revealed that instructors' perceptions were related: teachers' roles in the online environment, the methods for interacting with students, and teachers' expectations for their future educational careers. Slavin (1996) examined several empirical studies on collaborative learning and found that individual responsibility, group targets, and group interaction are the most critical factors in promoting learning achievement. With regards to collaborative online learning with diverse learners, Levin, Pascarella, and Terenzini (2005) found that CSCL offered students opportunities to collaborate with learners from different countries. CSCL allows diverse learners to experience new ideas and increase their cultural awareness (Levin, 2005).

In sum, the above studies focused on collaborative learning activities in online education and how they have been used to promote academic success of students, particularly culturally diverse learners. However, few empirical studies have researched the design of cross-cultural collaborative online learning frameworks for online instructors, particularly, instructional strategies instructors use to promote cross-cultural collaboration in online teaching to meet the needs of diverse learners (Arkoudis, Watty, Baik, Yu, Borland, Chang, \& Pearce, 2013; Mittelmeier et al., 2017; Yang et al., 2014). For example, Wang (2011) opined that there is a lack of instructional strategies for implementing cross-cultural online collaborative learning. Ahn, Yoon, and Cha (2015) suggested there is a need for online instructors to consider cultural diversity in online course design because online courses are developed based on personal values, preferences, expectations, and experiences. Thus, this study attempts to fill in gaps related to instructors' perspectives on designing a cross-cultural collaborative online framework for instructors. It also explores the challenges instructors encounter to facilitate cross-cultural collaborative learning.

\section{Conceptual Framework}

Collaborative online learning will serve as a conceptual framework to guide this study. Veerman (2000) defined collaborative learning as a pedagogical process that helps students discuss 
information and problems from different perspectives and to elaborate and refine their understanding to reconstruct (new) knowledge or to solve a problem. Cross-cultural collaborative learning provides students the opportunity to participate in online discussions and facilitates construction of knowledge (students are motivated to engage and participate in discussions) among students via responsibility to own their learning. CSCL helps students to create a new form of social knowledge-building structure in the cross-cultural collaborative online learning environment (Bruckman, 2006). It also provides students and instructors with a flexible online collaborative learning environment (Balakrishnan, 2011), wherein students have the chance to discuss content in depth and build knowledge from a distance (Shukor, Tasir, Van der Meijden, \& Harun, 2014). Harasim (2012) stated that "online collaborative learning theory (OCL) provides a model of learning in which students are encouraged and supported to work together to create knowledge: to invent, to explore ways to innovate, and, by so doing, to seek the conceptual knowledge needed to solve problems..." (p. 90). Harasim (2002) argued that OCL Theory of Discourse has three intellectual phases within online collaborative communities as new knowledge is synthesized: (a) idea-generating, (b) idea organization, and (c) intellectual convergence.

Levin (2005) contended that Computer-Supported Collaborative Learning (CSCL) offers students the chance to work with peers from different countries or geographic origin. These opportunities are important to the learning experience of students, as diverse peer contacts give students opportunity to generate new knowledge and promote more cultural awareness in online classrooms. Chou and Chen's (2008) study also found that online collaborative learning motivates students to engage in learning and provides support to students' learning outcomes. Hadjerrouit (2013) contended that online collaborative learning helps to increase student participation and contribution to knowledge construction. It also allows students to share their views and perspectives more than in the traditional face-to-face class because of the time and space (Hiltz \& Turoff, 2002).

However, collaborative online learning is criticized to lack time and space and differences of students' efforts. For example, studies (Capdeferro \& Romero, 2012; Garcia, 2012; Parker \& Chao, 2007) found that students experienced challenges in collaborative online learning as a result of time constraints for group members and differences in levels of commitments. Dirkx and Smith (2004) also found that a significant number of students do not equally benefit from collaborative online learning discussions (Oliveira, Tinoca, \& Pereira, 2011). Singh (2013) stated that the lack of non-verbal cues often creates challenges in text-driven communications. The study will use the concept of collaborative learning to serve as a lens on how instructors design instructional strategies to promote cross-cultural collaborative online learning.

\section{Methods}

This study used qualitative research design grounded theory (semi-structured interviews and archived online activities and observations) to investigate instructors' perspectives on designing instructional strategies that facilitate a cross-cultural collaborative framework. Grounded theory was chosen for this study because it is an exploratory research method that allows multi-faceted issues to emerge with no rigid definitions and provides opportunity for future theory and research to be more grounded related to participants' perspectives (Strauss \& Corbin, 1998). The following three research questions guided the study: 
(1) How do online instructors describe the instructional strategies that promote to design a cross-cultural collaborative online learning framework?

(2) How do online instructors describe the challenges that they face in designing crosscultural collaborative online learning framework?

(3) What are the resources online instructors use to design cross-cultural collaborative online learning framework in online teaching?

\section{Participants}

Forty online instructors from two universities in the Northeastern United States were recruited to participate in the study. Instructors included 18 Assistant Professors, 12 Associate Professors, and ten instructors across different academic disciplines (Colleges and Departments) and cultural backgrounds consisting ( $n=18$, Caucasian; 45\%), $(n=6$ [15\%], African American), $(n=7[17.5 \%]$, Hispanic), and $(n=9$ [22.5\%], Other (international faculty, instructors born and raised outside of the United States. Instructors consisted of $(n=17,42.5 \%)$ females and $(n=23$, $57.55 \%)$ males. Selected instructors were in the following colleges $(n=18,[45 \%]$ Colleges of Education), ( $n=7,[17.5 \%]$ Social Sciences), $(n=3,[7.5 \%]$ Sciences), and ( $n=12,[30 \%]$ Public Health). Instructors were selected based on the following criteria: (a) must have taught online/blended courses for at least two years at the higher education or university level. Instructors who have taught online/blended course(s) for two years might have gained knowledge in pedagogical skills and experience designing curriculum and cross-cultural collaborative frameworks in teaching online courses.

\section{Recruitment and Data Collection}

Instructor Interviews. The researcher conducted face-to-face semi-structured interviews with all instructors Spring and Fall semesters in 2017 (one year). All interviews took place on two university campuses at the offices of the selected instructors and lasted for 60 to 90 minutes. Interview questions included online instructors' perspectives on designing a cross-cultural collaborative online learning framework, cultural responsiveness in online learning, and instructional strategies used to facilitate collaborative activities in online learning. It also included challenges instructors face a designing cross-cultural collaborative framework in online learning, how to incorporate diversified curricula in online courses, how to promote intercultural interactions in online learning, and skills in designing instructional methods to motivate student participation and contribution to the construction of knowledge in an online learning environment (see Appendix A for interview questions).

The researcher used the research questions and conceptual framework to guide the formation of the semi-structured interview protocols. The researcher asked two experts in the field of instructional technology and online learning to verify interview questions. The experts reviewed, critiqued, and made suggestions as to which question to delete, revise, and include. For example, they suggested that the researcher add questions on how instructors design diversified curricula to enhance cross-cultural collaborative activities in the online classroom. Questions on challenges instructors face in designing cross-cultural collaborative framework and pedagogical activities that promote intercultural collaborations in online learning were revised. The researcher paid much attention to research control due to existing differences between subjects. Interviews were conducted in English, audio-recorded, and transcribed for analysis. Pseudonyms were used for the participants to protect their identity and confidentiality. 


\section{Course Documents, Online Activities, and Observational Data}

The researcher also had permission from instructors to observe their online classes, specifically, to observe instructional activities in each online course to gather instructional materials and review course archives. These included instructors' interaction with students, instructors' feedback to students, peer interaction, assignments, course expectations and directions, course projects, diversified reading materials, collaborative learning activities, how they facilitate discussions, communication, methods of assessment, and use of visuals, audio, and video materials. The researcher conducted observation of online activities and archives of one online course for each of the 40 instructors. This included instructors' interactions with students, support provided to students, inclusion of diverse reading resources, posts on chat rooms, instructor feedback, students reflection posts, and instructor response to students on the discussion boards. The aim was to find out how instructors facilitate cross-cultural collaborative online learning and best practices of teaching diverse learners in online settings. The researcher paid particular attention to how instructors facilitate cross-cultural interactions. For example, how students interact and collaborate with each other (interaction between domestic and international students), and how instructors design instructional activities based on the geographic or cultural backgrounds of students to enhance deeper learning (critical thinking to understand academic content). The researcher also observed archived online courses about how instructors differentiated instructional practices (learning activities to meet needs of individual students) to accommodate and meet the needs of diverse learners (students from different cultural backgrounds). The researcher took detailed field notes on instructional practices, students' posts in discussion forums, student-tostudent interactions, instructor-to-students interaction, and other online activities in the Learning Management Systems (LMS) and Course Management Systems (CMS).

\section{Data Analysis}

The researcher used constant comparative analysis to analyze interview and observational data via the coding procedures of using "open" "axial" and "selective" coding strategies throughout the study to help link the theoretical framework. The conceptual framework of this study (collaborative online learning) guided the coding process in exploring instructors' perspectives on designing a cross-cultural collaborative online learning framework. First, researchers analyzed archived online activities, field notes from interviews, and interview transcripts with constant comparative analysis (Charmaz, 2006) using qualitative software Nvivo (2015). The researcher carefully read thoroughly through all transcripts (instructor interviews and observational data notes), regarding how instructors design a cross-cultural collaborative online learning framework.

The researcher used open coding, labeling concepts, and defining and developing categories based on their properties and dimensions of the data. In the axial coding phase, the researcher assembled data to reflect how instructors design and promote cross-cultural collaborative online learning with the aim to help diverse learners achieve academic success. Conversely, the researcher reexamined all data to affirm identified subcategories and categories. This process allowed axial coding to remove redundant categories and organize data into larger categories.

With the selective coding, the researcher re-examined all data to address any redundancies to help establish themes. The researcher made copious use of "memos" via the codes, theoretical, and operational notes to conceptualize raw data throughout the coding process (Strauss \& Corbin, 
1998). To address trustworthiness and credibility of data analysis, the researcher triangulated several sources of data (i.e., instructors' interview transcripts, archived online activities, field notes, and memos obtained during the coding process) to represent online instructors' ability to design cross-cultural collaborative online learning frameworks. The researcher corroborated the three data sources to confirm themes that emerged from the data. The researcher used member checking with participants to confirm the themes (Merriam, 2009).

\section{Results}

The researcher identified the following major themes: (a) instructional strategies that facilitate design of cross-cultural collaborative online learning (e.g., group work, self-introductions and cultural awareness activity, computer-supported collaborative learning activity, the inclusion of global examples, and internationalized curriculum) and (b) challenges of designing a crosscultural collaborative online learning framework and teaching diverse learners.

\section{Instructional Strategies That Facilitate Design of Cross-Cultural Collaborative Online Learning}

The use of group work. Most instructors (30 of the 40 instructor-participants) reported using both large and small group work as an instructional strategy to promote cross-cultural collaboration in the online learning setting. Instructors (30 of the 40 instructor-participants) agreed that group work offers the opportunity for students to share ideas and make a meaningful contribution in the discussion forums because it allows each student to contribute to knowledge construction. An instructor in the social sciences noted: "I group my students into small groups to give the chance to know each other and share ideas and promote positive dialogue all to facilitate cross-cultural collaborations." Another instructor in public health commented:

I use group work to help students assume leadership and build knowledge as active participants in the online learning environment. I believe that group work helps to bring equal representation of ideas particularly to enable students from diverse backgrounds to participate and make their voices heard in building knowledge.

Most instructors (30 of the 40 instructor-participants) reported that small group work as an instructional strategy provides an enabling environment for students to collaborate with the content and exchange cross-cultural ideas on questions that the instructors posed. Interview and observational data showed that most instructors used group work to help to students engage in critical thinking of the content knowledge and questions that they discussed. For example, an instructor in education explained:

Group work in the online course helps students to connect their work with other students, promote dialogue and equity of participation. I see it as a way for students to share their work and viewpoints and build and engage collective knowledge.

Self-introductions and cultural awareness activity. The majority of the instructors (28 of the 40 participants) indicated that they use self-introductions and cultural awareness activities in the first week of class to help students familiarize themselves with one another and learn from each other about their cultural backgrounds and experiences. Cultural awareness is where students have the opportunity to share their cultural backgrounds with peers, particularly, what is shaped by their cultural heritage and upbringing, including language and experience. An instructor in education noted: "One instructional activity I used is self-introduction and cultural awareness to 
help students share their cultural backgrounds and experiences." Instructors (28 of the 40 participants) indicated that self-introduction and cultural awareness helps both students and instructors to understand the diversity students bring to the online classroom. Another instructor in the social sciences described her experience with self-introductions and cultural awareness activity:

I use self-introduction as an instructional activity to promote cross-cultural collaborations among students and instructors. This helps to identify and become aware of students, since it is hard to identify students in online learning, then it is essential for students to share their cultural and educational backgrounds to help foster cross-cultural dialogue and academic success.

Instructors (28 of the 40 participants) stated that cultural awareness activity helps to increase intercultural knowledge, understanding, and respect among students in the online learning community. It also helped students to share their cultural and educational experiences and share the various experiences that they bring to the online learning environment.

\section{Computer-Supported Collaborative Learning Strategy}

Another significant finding showed (34 of the 40 participants) expressed the use of a computer-supported collaborative learning strategy to help students to interact with their peers and instructors. Instructors indicated CSCL helped to increase students' participation and reduce the level of isolation in the discussion forum. An instructor in the health sciences department elaborated:

CSCL using email, Wikis, and blogs allow students to do in-depth deliberations and critical reflections on content to be discussed in the forum. Students can discuss issues in person in digital tools such as asynchronous conferencing (video conference, use of voice thread, and Skype) that facilitate cross-cultural interactions.

Interview and observed online activities data revealed that instructors (34 of the 40 participants) used CSCL tools such as discussion forums, chat rooms, voice thread, email, wikis, blogs, and other communicative tools in the Learning Management Systems (LMS) to promote social interactions and collaboration among students in the online learning environments. Most instructors (34 of the 40 participants) emphasized that CSCL as an instructional strategy offers opportunities for students to contribute to knowledge construction and higher order learning which helps to improve the academic performance of students. For example, most instructors (34 of the 40 participants) indicated that wikis as a tool serves a shared input and peer editing which enable collaborative shaping of content and knowledge. They contend that wikis as digital device allow students to organize, manage, and store information to produce collaborative learning.

Furthermore, instructors reported that voice thread, Google Docs, and GoToMeeting tools in the LMS allow two or more students to simultaneously work on a single shared paper or documents or archived artifacts, which helps them to continuously cross-collaborate on ideas and content knowledge (Anisetty \& Young, 2011; Koh \& Lim, 2012). Google Docs store data and documents over time and space, where students assess various individual contributions to help them engage in collaborations over time (Anisetty \& Young, 2011; Koh \& Lim, 2012). An instructor in the sciences commented: 
I use voice thread to support and promote interaction in an online course; I use the built-in voice tools to encourage and increase cross-cultural collaboration of students via feedback to comments, asynchronous audio discussion, video lectures and demonstrations to explain concepts with examples to students.

Instructors (34 of the 40 participants) indicated that social and teaching presence enable students' engagement and motivation to contribute to cross-collaborative learning and interactions. They emphasized that the use of videos and other digital tools in the LMS helps to establish activities that facilitate cross-cultural collaboration of students in the online learning environment (Das, 2012).

\section{The Inclusion of Global Examples and Internationalized Curriculum}

International curriculum is defined as the infusion of international examples or themes into the learning content in online course. It also includes the ability of instructors to incorporate global contents to help international students understand the content or concept being discussed. Examples include students working on reading materials with global contents where students have the chance to do intercultural interaction. Instructors in the social sciences, public health, and education (27 of the 40 participants) reported that incorporating global contents (e.g., diverse reading materials) in their online courses helps to encourage and motivate students to participate in online discussion.

Further, instructors (27 of the 40 participants) agreed that the use of examples of global content helps to engage students with instructional designs infused with international content. For example, an instructor in the public health indicated: "I think to incorporate global content and examples in an online courses helps to encourage intercultural interaction of students, where because international and diverse students can relate to the content knowledge or curriculum." Instructors (27 of the 40 participants) expressed that designing international content via inclusion of global examples students' engagement and co-construction of knowledge to make students become active participants in the discussion forum. For example, Arkoudis et al., (2013) suggested that incorporating internationalized content promoted collaboration among students in the online learning setting. A participant in the social sciences in the study agreed with these findings:

I teach global education and always include international content and examples to help diverse students contribute to construction of knowledge, since diverse learners bring diverse experiences to the online learning it is important to create and engage them with both local and international content.

Interview and online activities data about instructors in education, social sciences, and health sciences ( 37 of the 40 participants) revealed that they used global and international content in their online courses to facilitate intercultural engagement. However, instructors in the sciences failed to incorporate diverse content and materials to support students from different cultural backgrounds and experiences. Overall, instructors indicated that infusing international content and global examples in online courses helps to address the needs of culturally diverse students. Further, the use of diverse resources into an online learning curriculum helps to broaden the scope and participation of students from diverse backgrounds. 


\section{Challenges of Designing a Cross-Cultural Collaborative Online Learning Framework and Teaching Diverse Learners}

The majority of the instructors (32 of the 40 participants) expressed that they have challenges in facilitating cross-cultural collaborative learning for students from different cultural backgrounds. An instructor in education noted that: "I have challenges grouping students based on their cultural backgrounds because you can't just look at the photos and group them to facilitate intercultural interaction." Instructors (32 of the 40 participants) emphasized that it is difficult to design the course content to meet the needs of students. Another statement from an instructor in the sciences program stated:

I teach science and have had limited professional training about the best practices or instructional strategies to incorporate diverse content in an online learning environment. Again, attending to the cultural differences between students regarding their interactions and motivation is hard for me to facilitate and guide students to achieve.

Further, instructors' (32 of the 40 participants) response during interviews revealed that there are challenges to identify students based on their cultural preferences and learning needs in online learning environments. For instance, an instructor in education stated: "It is challenging to design a cross-cultural collaborative framework in online courses because of the difficulties with student identification and cultural barriers." Instructors (32 of the 40 participants) felt that it is easy to design an online course with diverse resources because of the content one teaches. For example, an instructor stated that: "The fact that you design and infuse diverse content and knowledge is not enough to promote diverse students' participation." For example, an instructor in the sciences program stated:

It is hard to determine students' cultural and social backgrounds or experiences in the online learning environment because I don't want to stereotype students on their ethnicity. I also have the difficulty of attending to the learning and cultural differences of students as a result of the asynchronous format. I don't have the skills and knowledge to differentiate my instruction to meet students' needs.

Instructors also stated that language barriers of some students often create challenges for them to facilitate intercultural interactions in online learning environments. Instructors emphasized that language barriers and communication issues affect their interactions with some international students because it is challenging to manage non-verbal interactions in the online learning environments. An instructor in education commented: "Language barriers pose lots of challenges for me as an online instructor to manage and create opportunities for students to interact with each other."

\section{Discussion}

This paper explored instructors' perspectives on designing a cross-cultural collaborative online learning framework. This paper also examined the challenges that instructors encountered in designing cross-cultural collaborative online activities. That is, knowledge instructors have instructional strategies to design diversified curricula to meet the needs of and teach students from diverse backgrounds. Two major themes emerged from the study, namely, (a) instructional strategies that facilitate designing a cross-cultural collaborative online learning include activities 
consisting of group work, self-introductions, and cultural awareness activities; computersupported collaborative learning activities; and the inclusion of global examples and internationalized curriculum, and (b) challenges of designing a cross-cultural collaborative online learning framework and teaching diverse learners. First, most the instructors agreed that instructional approaches such as using group work, self-introductions, CSCL, global examples, and internationalized curriculum help to facilitate cross-cultural collaborative online learning.

Findings lend support to the assertion that instructional strategies listed above (group work, self-introductions and cultural awareness activities, computer-supported collaborative learning activities, and the inclusion of global examples and internationalized curriculum) help to promote intercultural interactions between instructors and students. These activities helped students to share their cultural and social experience, which helped them to become aware of their peers' backgrounds and the experiences that they bring to the online learning environment as well as the pedagogical approach instructors should use to provide effective learning (e.g., McDonough \& Foote, 2015; Schreiber \&Valle, 2013). Findings imply that to teach in online learning, instructors must take into consideration the instructional approaches that meet the needs of diverse students and can facilitate intercultural interactions. Observations from online learning teaching and interviews showed that incorporating local and international examples into an online curriculum helps students to relate to reading materials in the construction of knowledge in online courses. These will provide important insights into students' learning in online education.

Furthermore, to design an effective cross-cultural collaborative online learning framework, the findings revealed that instructors should incorporate instructional activities or assignments and projects that will motivate students to collaborate with each other to master academic contents and concepts learned in the online learning community. Importantly, findings suggest that instructors need to design cross-cultural collaborative online frameworks that promote interactions among students in online learning environments. The findings indicated that it is important for instructors to make themselves available in large-scale online courses, where students can ask questions and interact via group work and collaborative learning to foster a strong sense of community to motivate students for active participation and the construction of knowledge. According to Chen and Chen (2015), study group as an instructional activity can promote an intercultural interaction in the online community, facilitate students' motivation for learning, and broaden students' perspectives of the content knowledge.

As stated in the conceptual framework, CSCL encourages students to contribute to construction of knowledge through social interactions in building knowledge in a cross-cultural collaborative online learning environment (Bruckman, 2006). According to Balakrishnan (2011), CSCL provides students and instructors the flexibility to discuss contents in depth and build knowledge from a distance in an online collaborative learning environment (Shukor, Tasir, Van der Meijden, \& Harun, 2014). According to Bliss and Lawrence (2009), cultural awareness in online classrooms helps to increase intercultural knowledge, understanding, and respect among students in the classroom. This shows that the use of best practices and online activities in an online course helped instructors and students share ideas and discuss issues, which allowed students to become active participants and make meaningful contributions to the learning contents or concepts.

Second, interview and observational data showed that instructors faced the challenges of identifying students based on their race or ethnic backgrounds, thus affecting instructors' ability to design cross-cultural collaborative activities to meet academic needs of individual students. 
Rogers et al., (2007) reported that the lack of cultural awareness by instructors could lead to misinterpretations or translate minority cultures into different contexts in online learning environments. This implies that instructors, particularly science instructors, need professional development training or workshops on how to incorporate diverse resources to meet the needs of students in the online learning environments. Findings support Parrish and Linder-VanBerschot's (2010) study that concluded that awareness of cultural dimensions can help online instructors develop a better understanding of the cultural differences among students and have knowledge awareness of their cultural orientations and biases ingrained in their online teaching. Henderson (2007) stated that teachers must develop multicultural learning contents in online learning to reflect the significance of integrating students' diverse cultural values, perspectives, and multiple ways of teaching to promote equity in an online course.

The findings for the present study showed that instructors faced challenges regarding instructional skills to design cross-cultural collaborative activities in online learning to provide support and incorporate multicultural teaching contents for diverse students. Results revealed that science instructors lacked the knowledge and skills to design cross-instructional activities that account for students' backgrounds and experiences. Instructors (26 out of the 40 participants) failed to tap students' cultural experiences as a resource to promote discourse and engagement among students in online classrooms. Most science instructors (two out of the three) failed to incorporate diverse learning contents in their online courses. For example, the majority of science instructors failed to provide feedback to students' responses and had no instructional activities to help facilitate intercultural interactions among students. The findings indicated that most instructors' encountered challenges related to designing and facilitating culturally mixed groups based on equal representation of race/ethnicity, age, and gender. For example, most instructors (34 out of the 40 instructor participants) stated that it takes extra time to promote cross-cultural collaboration in an online setting as it takes time and effort on the part of the instructors to know the background of all students to be able to develop courses and questions that meet the cognitive and social levels of students. Instructors reported that it is challenging to design an instructional activity to create a diverse group because they do not know the cultural identity of all students especially in a large-scale online course. Hence it is difficult to design and develop mixed groups and to help students play an active role in knowledge-building in cross-cultural collaborative online learning.

These findings build on literature on instructional strategies that facilitate social and cultural interaction interactions during collaborative learning activities in an online setting (Ahn et al., 2015; Hannon, \& D’Netto, 2007; Mittelmeier et al., 2017; Qayyum, 2016). This study has shown the perceptions and understanding of instructors' ability to design and incorporate crosscultural collaborative learning activities that promote intercultural interactions between instructors and students. Most importantly, the findings of this study provide practical guidelines to online instructors about instructional strategies to facilitate cross-cultural collaborative online learning and the academic success of students, particularly those from diverse cultural backgrounds. It also seeks to highlight the challenges instructors' encounter in designing and implementing strategies and incorporate diverse resources to promote cross-cultural collaborative online learning.

\section{Designing a Cross-Cultural Collaborative Online Learning Framework for Online Instructors}

To design and execute a cross-cultural collaborative online learning framework for instructors, they need to understand and have skills such as the ability to incorporate diverse resources and content to help engage, motivate, and promote students' intercultural dialogue. These include the following: 
Table 1

Designing Pedagogical Activities to Enhance Cross-Cultural Collaborative Online Learning for Online Instructors

\begin{tabular}{|c|c|}
\hline Design Stage & Pedagogical Activity/Framework \\
\hline $\begin{array}{l}\text { Planning and } \\
\text { organization }\end{array}$ & $\begin{array}{l}\text { - In the first week of an online course, instructors must develop self- } \\
\text { introduction or cultural awareness activity for students to share their } \\
\text { social, cultural, and educational backgrounds with each other as well } \\
\text { as instructors to learn about the student population in the online setting. } \\
\text { Instructors should infuse into the online curriculum introductory } \\
\text { activities to enable students to understand prior knowledge and } \\
\text { experiences of students. The purpose is to promote cross-cultural } \\
\text { dialogue to encourage students to bring their diverse backgrounds to } \\
\text { online classrooms. } \\
\text { Instructors must develop well-planned, monitored assignments and } \\
\text { intercultural interactions to help meet the needs of increasingly diverse } \\
\text { student populations in the online learning environment. It will help } \\
\text { instructors to provide scaffolded online discourse construction and } \\
\text { offer opportunities for students to take advantage of the content } \\
\text { knowledge (O'Connor \& Mcdonald, 2015). } \\
\text { Instructors must provide students with clear, adequate, and concise } \\
\text { expectations, guidance, directions, and when appropriate, forward } \\
\text { responses to students' questions to all students to avoid duplication of } \\
\text { information. } \\
\text { Instructors must design online courses to bridge the geographic and } \\
\text { cultural backgrounds to give students the chance to share their thoughts } \\
\text { and understanding before postings (O'Connor \& Mcdonald, 2015). }\end{array}$ \\
\hline $\begin{array}{l}\text { Pedagogical } \\
\text { strategies to } \\
\text { include in } \\
\text { designing cross- } \\
\text { cultural } \\
\text { collaborative } \\
\text { online learning }\end{array}$ & $\begin{array}{l}\text { - Instructors must make themselves available at all times to answer } \\
\text { student online questions or should make time to respond to their } \\
\text { comments in online discussion forums. An important suggestion is for } \\
\text { instructors to create threads based on students' national backgrounds } \\
\text { or educational backgrounds to help students identify topics or concepts } \\
\text { by their interests or contexts (Hew, 2018; Liyanagunawardena et al., } \\
\text { 2015). } \\
\text { - Instructors must design online courses to bridge the geographic and } \\
\text { cultural backgrounds to give students the chance to share their thoughts } \\
\text { and understanding before postings (O'Connor \& Mcdonald, 2015). } \\
\text { Instructors must create an enabling, rich, and caring online community } \\
\text { via designing diverse resources and instructional methods for students } \\
\text { to share ideas, responses, and discussions. Such a community will } \\
\text { empower students to have equal access to an online discussion and } \\
\text { contribute to the construction of knowledge (Hew, 2016). } \\
\text { Instructors must design online courses that consider students' diversity } \\
\text { and cultural backgrounds. The content of the curriculum must reflect } \\
\text { students' cultural experiences and preferences. }\end{array}$ \\
\hline
\end{tabular}




\begin{tabular}{|c|c|}
\hline \multicolumn{2}{|c|}{$\begin{array}{l}\text { Table } 1 \text { (continued) } \\
\text { Designing Pedagogical Activities to Enhance Cross-Cultural Collaborative Online } \\
\text { Learning for Online Instructors }\end{array}$} \\
\hline Design Stage & Pedagogical Activity/Framework \\
\hline $\begin{array}{l}\text { Inclusion of } \\
\text { multicultural } \\
\text { learning contents } \\
\text { in online } \\
\text { learning }\end{array}$ & $\begin{array}{l}\text { - To facilitate smooth cross-cultural collaborations among students, } \\
\text { instructors must create flexible activities and options for students to } \\
\text { have control over time and space. Instructors should offer students the } \\
\text { chance to choose from a variety of activities to achieve better academic } \\
\text { performance. } \\
\text { - Instructors should promote social, teaching, and cognitive presence to } \\
\text { help create connections with students based on their cultural } \\
\text { backgrounds. They should guide and facilitate learning experiences to } \\
\text { include providing course expectations, directions, guidance, and } \\
\text { diversified instructional curricula (Garrison, Anderson, \& Archer, } \\
\text { 2000). } \\
\text { There must be an inclusion of cultural competency strategies to } \\
\text { promote cross-cultural collaborative learning (Caffrey, Neander, } \\
\text { Markle, \& Stewart, 2005). }\end{array}$ \\
\hline $\begin{array}{l}\text { Facilitating } \\
\text { technology in } \\
\text { cross-cultural } \\
\text { collaborative } \\
\text { online learning }\end{array}$ & $\begin{array}{l}\text { - Instructors must use digital tools in the Learning Management Systems } \\
\text { and Course Management Systems to create an environment that } \\
\text { promotes consistent communications between students and instructors. } \\
\text { - Instructors must create links to the discussion forums, blogs, or wikis } \\
\text { in the LMS for students to ask questions as well as gather, share ideas, } \\
\text { and contribute to knowledge building via video-streamed sessions for } \\
\text { students to do video conferencing between instructors and students } \\
\text { (e.g., using Google Hangouts sessions) (Boettcher \& Conrad, 2016; } \\
\text { Hew, 2018). }\end{array}$ \\
\hline $\begin{array}{l}\text { Facilitating } \\
\text { interaction in } \\
\text { cross-cultural } \\
\text { collaborative } \\
\text { online learning }\end{array}$ & $\begin{array}{l}\text { - There must be the need for instructors to establish consistent } \\
\text { communication channels and feedback to students' questions and } \\
\text { responses to foster intercultural interaction as well as to create chances } \\
\text { for them to mentor and promote students' construction of knowledge. } \\
\text { - Instructors must incorporate strategies that highlight interpersonal } \\
\text { understanding, and social networking diversity to help online students } \\
\text { exchange ideas and experiences with each other (Mittelmeier, Heliot, } \\
\text { Rienties, \& Whitelock, 2016). }\end{array}$ \\
\hline
\end{tabular}

\section{Implications}

The study highlights several implications for instructors and instructional designers on the need to incorporate instructional strategies to design a cross-cultural collaborative framework in online learning. Cross-cultural collaborative online learning promotes intercultural communication progress between students to students and instructors to students. Another implication of this study is that it calls on instructors and instructional designers to design an online learning framework that takes into account individual students' cultural backgrounds and experiences, activities that facilitate cultural responsiveness in online classrooms, and the need to infuse in the curriculum diverse resources, international contents, and global examples to help 
students from culturally diverse backgrounds. The present study contributes to online collaborative learning in that it explored various instructional strategies and it impacts on intercultural interactions between instructors and students and academic success. The present study showed that designing cross-cultural collaborative learning activities, when implemented effectively, helps students in collaborative knowledge building via consistent intercultural interactions in online learning environments.

Limitations. In this article, a qualitative research design (interviews and observation of online learning activities) was used to explore how instructors design instructional strategies to promote cross-cultural collaborative learning activities in online learning. In doing so, many limitations of the study are noted. First, the study is a small representation of online instructors in higher education against the backdrop of online instructors representing universities in the United States. Thus, it is worthy to conduct a quantitative study about both students and instructors' perception and understanding of the instructional strategies that promote cross-cultural collaborative learning in online learning. Future research could replicate this study across different universities in other states to learn from instructors across academic programs about instructional activities that facilitate cross-cultural collaborative online learning environments. Moving forward, future research could collect instruction questionnaire data to examine which types of instructional strategies facilitate intercultural interactions to help students become active participants in online learning environments. There is the need for further studies to understand how instructors implement and incorporate diverse resources to help students, particularly culturally diverse students, to participate in cross-cultural collaborative online learning with their peers and instructors.

\section{Conclusion}

This study explored online instructors' perspectives on designing a cross-cultural collaborative online learning framework. The study also investigated the challenges instructors face to design cross-cultural collaborative online learning frameworks. Findings showed two major themes comprising (a) instructional strategies that facilitate designing a cross-cultural collaborative online learning, (namely, group work, self-introductions and cultural awareness activity, computer-supported collaborative learning activity, the inclusion of global examples, and internationalized curriculum) and (b) challenges of designing a cross-cultural collaborative online learning framework and teaching diverse learners. The findings of the study agree with the online collaborative learning theory that a cross-cultural collaborative framework motivates students to engage in learning and become active participants and provides support to students to make meaningful contributions in the construction of knowledge in an online community (Chou \& Chen, 2008). However, instructors in the sciences expressed challenges in the design of cross-cultural collaborative online course curriculum to promote diverse students' participation and contributions to knowledge building. The findings also suggested that most instructors lacked pedagogical skills in designing cross-cultural collaborative online learning framework to address the needs of diverse learners in online learning classrooms, especially their ability to design cross-cultural collaborative online frameworks that account for students' cultural differences, as well as to incorporate diverse resources (local and internationalized contents) into the curriculum to help meet the students' needs. 


\section{References}

Ahn, M. L., Yoon, H., \& Cha, H. (2015). Cultural sensitivity and design implications of MOOCs from Korean learners' perspectives: Case studies on edX and Coursera. Educational Technology International, 16(2), 201-229.

Allen, E., \& Seaman, J. (2017). Grade level: Tracking online education in the United States. Babson Survey Research Group Report. Retrieved from: http://www.onlinelearningsurvey.com/reports/gradelevel.pdf

Allen, E., \& Seaman, J. (2016). Grade level: Tracking online education in the United States. Babson Survey Research Group Report. Retrieved from http://www.onlinelearningsurvey.com/reports/gradelevel.pdf

Anisetty, P., \& Young, P. (2011). Collaboration problems in conducting a group project in a software engineering course. Journal of Computing Sciences in Colleges, 26(5), 45-52.

Arkoudis, S., Watty, K. Baik, C., Yu, X., Borland, H., Chang, S., \& Pearce, A. (2013). Finding common ground: Enhancing interaction between domestic and international students in higher education. Teaching in Higher Education, 18(3), 222-235. http://dx.doi.org/10.1080/13562517.2012.719156.

Baker, C., \& Taylor, S. L. (2010). The importance of teaching presence in an online course. Madison, WI: Magna Publications.

Blasco-Arcas, L., Buil, I., Hernandez-Ortega, B., \& Sese, F. J. (2013). Using clickers in class. The role of interactivity, active collaborative learning and engagement in learning performance. Computers \& Education, 62, 102-110.

Bliss, C. A., \& Lawrence, B. (2009). From posts to patterns: a metric to characterize discussion board activity in online classes. Journal of Asynchronous Learning Networks, 13(2), 15-32. Retrieved from https://onlinelearningconsortium.org/read/online-learning-journal/

Boettcher, J.V., \& Conrad, R-M. (2016). The online teaching survival guide: Simple and practical pedagogical tips. San Francisco, CA: Jossey-Bass.

Caffrey, R. A., Neander, W., Markle, D., \& Stewart, B. (2005). Improving the cultural competence of nursing students: Results of integrating cultural content in the curriculum and an international immersion experience. Journal of Nursing Education, 44(5), 234-240.

Capdeferro, N., \& Romero, M. (2012). Are online learners frustrated with collaborative learning experiences? The International Review of Research in Open and Distance Learning, 13(2), 26-44. Retrieved from http://www.irrodl.org/index.php/irrodl/article/view/1127

Charmaz, K. (2006). Constructing grounded theory: A practical guide through qualitative analysis. London: Sage.

Dawson, S. (2006). A study of the relationship between student communication interaction and sense of community. The Internet and Higher Education, 9(3), 153-162.

http:////dx.doi.org/10.1016/j.eheeduc.2006.06.007

Charmaz, K. (2006). Constructing grounded theory: A practical guide through qualitative analysis. London: Sage.

Chou, P. N., \& Chen, H. H. (2008). Engagement in online collaborative learning: A case study using a Web 2.0 tool. Journal of Online Learning and Teaching, 4(4), 574-582. 
Das, S. (2012). Increasing instructor visibility in online courses through mini-videos and screencasting. In Online student engagement tools and strategies (pp. 8-9). Madison, WI: Magna Publications.

Dirkx, J. M., \& Smith, R. O. (2004). Thinking out of a bowl of spaghetti: learning to learn in online collaborative groups. In T. S. Roberts (Ed.), Online collaborative learning: Theory and practice (pp. 132-159). Hershey: Information Science Publishing.

Fozdar, F., \& Volet, S. (2012). Intercultural learning among community development students: Positive attitudes, ambivalent experiences. Community Development, 43 (3) 361-378, doi: $\underline{10.1080 / 15575330.2011 .621085}$

Garcia, P. G. (2012). Collaborative learning activities in online courses: issues and strategies. ASEAN Journal of Open Distance Learning, 4(1), 1-16.

Garrison, D. R., Anderson, T., \& Archer, W. (2000). Critical thinking in a text-based environment: Computer conferencing in higher education. Internet and Higher Education, 11(2), 1-14.

Gu, X., Wang, H., \& Mason, J. (2017). Are they thinking differently: a cross-cultural study on the relationship of thinking styles and emerging roles in computer- supported collaborative learning. Journal of Educational Technology \& Society, 20(1),13. Retrieved from https://www.j-ets.net/ETS/issues1a6a.html?id=75

Gunawardena, C. N., Nolla, A. C., Wilson, P. L., Lopez-lslas, J. R., Ramirez-Angel, N., \& MegchunAlpizar, R. M. (2001). A cross-cultural study of group process and development in online conferences. Distance Education, 22(1), 85-121.

Hadjerrouit, S. (2013). A framework for assessing the pedagogical effectiveness of wiki-based collaborative writing: results and implications. Interdisciplinary Journal of E-learning and Learning Objects, 9, 29-49.

Hannon, J., \& D’Netto, B. (2007). Cultural diversity online: Student engagement with learning technologies. International Journal of Educational Management, 21(5), 418-432.

Harasim, L. (2012). Learning theory and online technology: How new technologies are transforming learning opportunities. New York, NY: Routledge Press.

Henderson, L. (2007). Theorizing multiple cultures instructional design model for e- learning and eteaching. In A. Edmundson (Ed.), Globalized e-learning cultural challenges (pp. 130-153). Hershey: Information Science Publishing.

Hew, K. F. (2018). Unpacking the strategies of ten highly rated MOOCs: Implications for engaging students in large online courses. Teachers College Record 120, 010308.

Hiltz, S. R., \& Turoff, M. (2002). What makes learning networks effective? Communications of the $A C M, 45(4), 56-59$.

Hrastinski, S. (2009). A theory of online learning as online participation. Computers \& Education, $52(1), 78-82$.

Kearney, M. (2004). Classroom use of multimedia-supported predict-observe-explain tasks in a social constructivist learning environment. Research in Science Education, 34, 427-453

Koh, E., \& Lim, J. (2012). Using online collaboration applications for group assignments: the interplay between design and human characteristics. Computers \& Education, 59(2), 481496. 
Levin, P. (2005). Successful teamwork. McGraw-Hill Education, New York, NY

Liyanagunawardena, T. R., Kennedy, E., \& Cuffe, P. (2015). Design patterns for promoting peer interactions in discussion forum in MOOCs. Retrieved from http://www.openeducationeuropa. eu/en/article/Design-patterns-for-Open-Online-Teachingand-Learning-Design-Paper-42-7

McDonough, K, \& Foote, J. A. (2015). The impact of individual and shared clicker use on students' collaborative learning. Computers \& Education, 86, 236-249.

Merriam, S. B. (2009). Qualitative research: A guide to design and implementation. San Francisco, CA: Jossey-Bass.

Mittelmeier, J., Rienties, B., Tempelaar, D., \& Whitelock, D. (2017). Overcoming cross-cultural group work tensions: Mixed student perspectives on the role of social relationships. Higher Education. http://dx.doi.org/10.1007/s10734-017-0131-3.

Mittelmeier, J., Rienties, B., Tempelaar, D., Hillaire, G., \& Whitelock, D. (2018). The influence of internationalized versus local content on online intercultural collaboration in groups: A randomized control trial study in a statistics course. Computers \& Education, 118, 82-95.

Moore, P., \& Hampton, G. (2015). 'It's a bit of a generalization, but...': Participant perspectives on intercultural group assessment in higher education. Assessment \& Evaluation in Higher Education, 40 (3), 390-406 doi: 10.1080/02602938.2014.919437

Nguyen-ngoc, A. V., \& Law, E. L. (2009). Analysis of weblog-based facilitation of a fully online cross-cultural collaborative learning course. In U. Cress, V. Dimitrova, \& M. Specht (Eds.), Learning in the synergy of multiple disciplines $S E$ - 19 (pp. 181-195). Berlin, Germany: Springer. doi:10.1007/978-3-642-04636-0_19

O’Connor, E. A., McDonald, F., Ruggiero, M. (2015) Scaffolding Complex learning: Integrating 21st century thinking, emerging technologies, and dynamic design and assessment to expand learning and communication opportunities. Journal of Educational Technology Systems 43(2): 199-226. https://doi.org/10.2190/ET.43.2.g

Oliveira, I., Tinoca, L., \& Pereira, A. (2011). Online group work patterns: how to promote a successful collaboration. Computers \& Education, 57(1), 1348-1357.

Parker, K., \& Chao, J. (2007). Wiki as a teaching tool. Interdisciplinary Journal of Knowledge and Learning Objects, 3, 57-72.

Parrish, P., \& Linder-vanberschot, J. A. (2010). Challenges of multicultural instruction. International Review of Research in Open and Distance Learning, 11(2), 1-19. Retrieved from http://www.irrodl.org/index.php/irrodl/article/view/809/1497

Powell, K. C., \& Kalina, C. J. (2009). Cognitive and social constructivism: developing tools for an effective classroom. Education, 130(2), 241-251.

Popov V., Noroozi O., Biemans H. J. A., Mulder M. (2012) Computer supported intercultural collaborative learning: A study on challenges as perceived by students. In A. Ravenscroft, S. Lindstaedt, C. D. Kloos, \& D. Hernández-Leo (Eds.) 21st century learning for 21 st century skills. EC-TEL 2012. Lecture Notes in Computer Science, 7563. Springer, Berlin, Heidelberg.

Qayyum, A. (2016). Culture and online learning: Global perspectives and research. Editors I. Jung \& C. N. Gunawardena, (Eds.), Sterling, VA: Stylus Publishing, 2014, American Journal of Distance Education, 30(2), 125-127. 
Rienties, B., Héliot, Y., \& Jindal-Snape, D. (2013). Understanding social learning relations of international students in a large classroom using social network analysis. Higher Education, 66 (4), 489-504, doi:10.1007/s10734-013-9617-9

Rogers, P. C., Graham, C. R., \& Mayes, C. T. (2007). Cultural competence and instructional design: Exploration research into the delivery of online instruction cross-culturally. Educational Technology Research and Development, 55(2), 197-217.

Schreiber, L. M., \& Valle, B. E. (2013). Social constructivist teaching strategies in the small group classroom. Small Group Research, 44(4), 395-411.

Singh, R. (2013). Collaboration in the cloud: role of interaction and online collaborative tools in enhancing knowledge creation in virtual environments. Journal of Information \& Knowledge Management, 12(04), 1350030-1350031;1350030-1350112.

Shukor, N. A., Tasir, Z., Van der Meijden, H., \& Harun, J. (2014). Exploring students' knowledge construction strategies in computer-supported collaborative learning discussions using sequential analysis. Educational Technology and Society, 17(4), 216-228. Retrieved from https://www.j-ets.net/ETS/issuesf8d4.html?id=65

Slavin, R. E. (1996). Research on cooperative learning and achievement: What we know, what we need to know. Contemporary Educational Psychology, 21(1), 43-69.

Slof, B., Nijdam, D., \& Janssen, J. (2016). Do interpersonal skills and interpersonal perceptions predict student learning in CSCL-environments? Computers \& Education, 97, 49-60. http://dx.doi.org/10.1016/j.compedu.2016.02.012.

Strauss, P. A., \& Young, U, S. (2011). 'I know the type of people I work well with': Student anxiety in multicultural group projects. Studies in Higher Education, 36 (7), 815-829. doi: $10.1080 / 03075079.2010 .488720$

Strauss, A., \& Corbin, J. (1998). Basics of qualitative research: Grounded theory procedures and techniques. Newbury Park, CA: Sage Publications.

Subramony, D. P. (2004). Instructional technologists' inattention to issues of cultural diversity among learners. Educational technology: The magazine for managers of change in education, (4), 19-24.

Turoff, M., Hiltz, S. R., Li, Z., Wang, Y., \& Cho, H. (2004). Online collaborative learning enhancement through the Delphi method. Turkish Online Journal of Distance Education, $7(2), 66-79$.

Wang, C. (2011). Instructional design for cross-cultural online collaboration: Grouping strategies and assignment design. Australasian Journal of Educational Technology, 27(2), 243-258.

Watson, R. T., Ho, T. H., \& Raman, K. S. (1994). Culture: a fourth dimension of group support systems. Communication of the ACM, 37(10), 45-55.

Yamazaki, Y., \& Kayes, D. C. (2004). An experiential approach to cross-cultural learning: A review and integration of competencies for successful expatriate adaptation. Academy of Management Learning \& Education, 3(4), 362-379.

Yang, J., Kinshuk, Yu, H., Chen, S., \& Huang, R. (2014). Strategies for smooth and effective crosscultural online collaborative learning. Educational Technology \& Society, 17 (3), 208-221. Retrieved from https://www.j-ets.net/ETS/issues619c.html?id=62 


\section{Appendix A: Interview Protocol}

1. Tell me about your online/blended teaching experience. How has it been?

2. What is your philosophy of teaching online/blended course(s)?

3. How do you describe your role as a facilitator in your online teaching?

4. Tell me how what instructional activities you use in your online teaching or course?

5. How do you understand collaborative online/blended learning?

6. What are your perspectives on collaborative online/blended learning?

7. Can you share with me how you facilitate collaborative activities in online/blended learning?

8. Explain how you design collaborative activities in online/blended learning to promote student participation and understanding of the learning contents? Please give examples.

9. What are your perspectives on cross-cultural collaborative online learning?

10. Can you share with me how you design cross-cultural collaborative online learning framework? Please give example(s).

11. Tell me about your experience designing cross-cultural collaborative online learning framework? How do you design it? Please give an example.

12. Can you share with me the resources you use to design cross-cultural collaborative online learning frameworks?

13. What instructional or pedagogical activity(ies) do you incorporate in designing crosscultural collaborative online learning framework? Can you with me more examples.

14. Can you share with me how you incorporate diverse learning resource in your online/blended course to promote intercultural interactions?

15. What instructional activities do you use to promote student interaction in online/blended learning? Please give an example.

16. What are your perspectives on cultural responsiveness in online/blended learning?

17. Can you share with me how you promote or incorporate cultural responsiveness in your online/blended course(s)?

18. How do you incorporate cultural responsiveness into cross-cultural collaborative online learning framework? Please give an example.

19. How do you use communication tools such as emails, online chats, videos, and discussion board in designing a cross-cultural collaborative online/blended framework? Please provide an example?

20. Describe your experience designing cross-cultural online collaborative learning framework and facilitating an online course? Please explain with examples.

21. Describe the benefits of designing a cross-cultural collaborative online learning framework? Can you share with me more examples?

22. Describe the benefits of cross-cultural collaborative online learning framework to students? Give an example.

23. What are the major challenges you face or encounter in designing cross-cultural collaborative online learning framework? Please provide specific examples.

24. Describe the strategies you use to address the challenges in designing cross-cultural collaborative online learning framework? Please give some examples.

25. How do you use cross-cultural online collaborative framework to differentiate your instruction in online teaching? Please give an example. 